\title{
Price Spikes in the Italian Electricity Market: An Economic Analysis
}

\author{
Stefano Zedda, Giovanni Batista Masala \\ Department of Economic and Business Sciences, University of Cagliari, Cagliari, Italy \\ Email: szedda@unica.it,gb.masala@unica.it
}

How to cite this paper: Zedda, S. and Masala, G.B. (2019) Price Spikes in the Italian Electricity Market: An Economic Analysis. Modern Economy, 10, 2145-2156. https://doi.org/10.4236/me.2019.109135

Received: August 27, 2019

Accepted: September 26, 2019

Published: September 29, 2019

Copyright $\odot 2019$ by author(s) and Scientific Research Publishing Inc. This work is licensed under the Creative Commons Attribution International License (CC BY 4.0).

http://creativecommons.org/licenses/by/4.0/

\begin{abstract}
Since their liberalization, the electricity markets are characterized by a rather high volatility, which includes price spikes as one of the stylized and specific characteristics of this market. In this paper, we investigate the factors and mechanisms determining these spikes. Based on the Italian electricity market data, we perform a specific analysis of the auctions mechanisms and of the hourly bid and offer of electricity characteristics, for determining how and why do price spikes occur.
\end{abstract}

\section{Keywords}

Electricity Markets, Auctions, Bid and Offer, Price Spikes, Probit Model

\section{Introduction}

As a consequence of the liberalization of electricity markets, in the largest part of western countries the electricity power market is based on a day-ahead auction mechanism, where, for each hour, each producer and each distributor can place its offer, and the price is subsequently determined as the one that allows the electricity power bid and offer to be balanced. This auction mechanism, due to the variability of the electricity demand, determines a continuous variation in the resulting prices. Thus, the electricity prices time series have often been analyzed by statistical models similar to the ones developed for financial markets, as like stock exchange or similar. Indeed, some characteristics are specific to electricity markets. Among these, one of the stylized facts that characterize the electricity prices time series is the presence of price spikes, not necessarily related to corresponding variations in its demand quantity. Almost all the models in literature include this characteristic, which is well known in its effects, but not adequately analyzed in its mechanisms and determinants.

In this paper, we analyze in detail the Italian electricity market, in its 
day-ahead auction mechanism, including the single producer's behavior, and the aggregate bid and offer resulting curves. In this way, we can evidence the specific mechanisms that determine significant variations in prices, not due to demand variations.

We firstly investigate thoroughly the explanatory variables, which can affect spike prices by means of probit regression techniques. We highlight that high demand only explains part of the actual price spikes. Thus, the second step of the analysis is devoted to investigate in depth the auction mechanisms, taking into account the characteristics of the bid and ask curves coming from the auctions and of the single producer's behavior, so to find how and why do spikes occur.

The remainder of this paper is structured as follows. Section 2 reports the literature review; Section 3 investigates about the main features of the electricity markets, the auction mechanisms and the price spikes in the Italian Market. Section 4 concludes.

\section{Literature Review}

Price spikes are one of the stylized facts that characterize energy markets, and have been investigated from a theoretical point of view by several authors. Indeed, a large part of the literature is focused on spikes description and forecasting. Ultimately, the price peaks have been studied from a theoretical point of view, but few works have attempted to shed light on the real causes of the phenomenon. Our work aims to partially fill this gap. The most significant and recent contributions concerning electricity price modeling and the occurring of price spikes can be summarized as it follows.

Reference [1] interpret the time series of price spikes as a discrete-time point process and they forecast spikes for the Australian Market. Reference [2] additionally investigate price spikes across connected regions also in the Australian Market. Reference [3] survey the influence of exogenous variables (such as load, weather, capacity constraints) on the occurrence and intensity of price spikes in Australian Market. At this purpose, they apply the Heckman selection model. Reference [4] asserts that the occurrence of spikes increases whenever temperature deviates from its mean levels. Reference [5] investigate about spikes estimation through filtering techniques. Reference [6] treat simultaneous occurrence of spikes in several markets by applying an innovative dynamic model. Reference [7] use a stochastic regime-switching model to determine spikes. This model is indeed suitable to characterize the volatile nature of electricity prices. Reference [8] uses high frequency spot price data coming from several markets in order to estimate volatility and consequently the occurrence of price spikes.

Finally, A review of electricity price modeling is contained in [9].

\section{Electricity Markets}

\subsection{Main Characteristics of Electricity Markets}

The electricity markets are currently coping with important transformations 
with the introduction of the category of renewable energies. Since the years around 2000, the European Union went on a comprehensive energy market deregulation, aiming to a multinational energy market able to integrate renewable energy sources. The EU directive on the promotion of renewable energy sources, entered into effect in June 2009, setting national targets in the aim of reaching a minimum of $20 \%$ renewable energy sources (RES) share by 2020 .

A striking peculiarity of electricity markets is that electricity production and consumption must be in equilibrium at any time, to prevent network collapses. Indeed, the main reason lies in the fact that electricity as it is cannot be stored (except at prohibitive costs) so the energy required at all times must be immediately available, and all the electricity actually produced must be immediately consumed.

The main part of the power spot market is managed by means of a day-ahead market, where each producer (distributor) proposes its offer for the supply (demand) for each hour of the next day, specifying the requested price and the power quantity. The auction mechanism identifies the price which equilibrates demand and supply of power, and assigns the production slots to each producer which has offered a price lower or equal to the equilibrium price.

In Italy, the auction is administered by GME ("Gestore Mercati Energetici") which is a state managed company. Within this market, due to the particular structure of the Italian power grid, the auctions can be managed by regional zones, and the final price paid by customers refers to the so-called "single national purchase price" PUN ("Prezzo Unico Nazionale"), estimated for each hour through a weighted average of the zonal prices issued by the day-ahead market, where each zone weight depends on the actually traded quantities.

The PUN also represents the reference price of electricity recorded on the Italian power exchange (IPEX, Italian Power Exchange).

\subsection{The Auction Mechanism}

The day-ahead electricity power auction market can be considered as a Cournot oligopoly of $N$ power producers, each one able to choose the production level, and the minimum price they are accepting, but not the actual price they will receive, which is determined as the auction clearing price. For a survey of Cournot oligopoly in power markets, see [10]. In short, energy producers determine their own production aiming to maximize their profit supposing that the demand curves and the fixed competitors' output are known.

In general, a Cournot oligopoly with $N>1$ agents can be represented as it follows:

- A fixed number of agents, all producing the same homogeneous good, known to all agents;

- The agents do not cooperate, and each agent's output decision affects the good's price;

- Agents compete in quantities and price. Each one chooses it simultaneously 
to the other agents; in particular, each $i$ firm chooses quantity $q_{i}$ and price $p_{i}$;

- The market-clearing price $p^{*}$ of the good is determined by a commonly known function, which allows the good demand and offer to be balanced;

- All the agents offering their production at a price lower or equal to the clearing price are allowed to sell the offered quantity at the clearing price, while the producers offering at a price higher than the clearing price $p^{*}$ will have their offer not accepted;

- The agents are economically rational and act strategically, seeking to maximize their profit; agent $i$ has a marginal cost function $c_{i}\left(q_{i}\right)$, and its total profit $u_{i}$ is given by $u_{i}=q_{i} \cdot p^{*}-c_{i}\left(q_{i}\right)$.

Figure 1 provides a graphical description of the auction mechanism.

We note that the equilibrium price, and the associated quantity, are obtained from the intersection of the aggregate demand and supply curves. A change in the demand and supply curves therefore translates into an appreciable change in the equilibrium price.

\subsection{Prices Spikes in the Italian Power Market}

Price spikes are defined as the prices exceeding a preset threshold.

In literature, some different approaches are proposed. Some authors suggest to use log-price change thresholds, fixed (as in [11]) or variable (as in [12]).

Other authors suggest using a fixed threshold value for the whole time series under consideration (e.g. [13]; [1]; [2]). As our sample includes the daily values from 2012 to 2016, so including different market conditions, not correctly selected by a fixed threshold, similarly to [14] and [15] we computed the spike threshold as the price average plus three times its volatility recorded during the previous year.

More formally, we denote $P_{t}$ the electricity price at time $t$ (time unit is expressed in hours). We say that a price spike occurs whenever $P_{t}>\mu_{t}+3 \sigma_{t}$ where $\mu_{t}$ represents the mean price value and $\sigma_{t}$ denotes its volatility. Both quantities have been estimated by considering a rolling window of one-year data before time $t$. This definition allows classifying about $1 \%$ of price values as spikes.

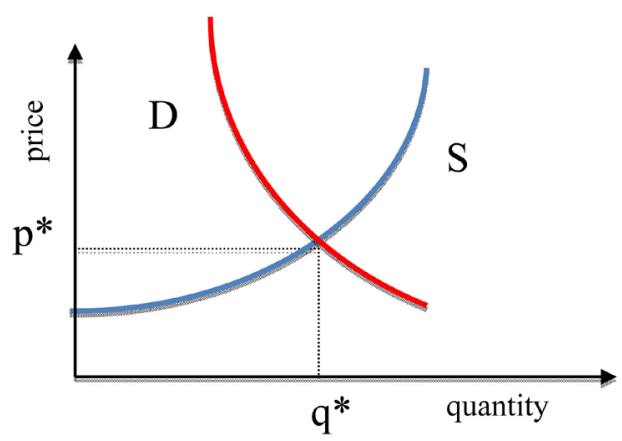

Figure 1. Day ahead auction graphical representation. Source: Authors elaboration. 


\subsection{Demand-Driven Spikes}

A statistical investigation highlights that spikes do not occur uniformly through time, indeed they are likely to cluster around particular periods. In this purpose, we analyzed the Italian electricity market behavior from 2005 to 2016. In the following figures, we picture the percentage of price spikes with respect to Year (Figure 2(a)), Month (Figure 2(b)), Day of the week (Figure 2(c)) and Hour (Figure 2(d)).

The evidences coming from the previous figures can be interpreted as due to the higher electricity power demand. In fact, price spikes more often occur around July and November as cooling and heating starts. With reference to the weekdays, the price spikes occurrence is almost constant in working days, but its incidence is drastically reduced on Saturdays and Sundays. Regarding the hours of typical occurrence, the spikes attain two maxima at around 11-12 a.m. and 6 p.m., which approximately coincides with the timing of higher electricity demand. Finally, we note that spikes occurrence is not homogeneous through years.

For a more precise quantification of the actual role of demand in inducing price spikes, we performed some probit regression, taking into account data from 2012 to 2016, for a total of 43,848 records.

The first regression only includes demand as explanatory variable, in its direct value and nonlinear transformations (squared and cubed value), and lagged values ( 2 and 5 hours). Results show that only small part of the spikes occurrence is explained by the demand volume, the resulting R-squared value being around 24\% (see model 1 in Appendix for details).

As the time span considered for our analysis includes important variations of production costs, we also verified if the introduction of some variables related to fuel costs could actually improve the estimation quality.

Thus, we also considered the effect of fuel prices such as crude oil and natural gas, which are one of the main determinants of the direct costs of fuel-based productions, and are expected to affect the resulting price for a given demand volume. Results show that these variables improve the estimation, raising the R-squared value to around 33\% (see model 2 in Appendix for details).

These results proof that the demand variations are not sufficient to explain the price spikes probability to occur, but an important part of its occurrence is still unexplained.

\subsection{Non-Demand-Driven Spikes}

For evaluating which mechanism can induce these results, we analyzed in depth the auction mechanism and bid and offer curves characteristics for determining how and why these "unexplained" price spikes do occur.

- Price elasticity

The price elasticity (of supply or of demand) is a measure used in economics to quantify the responsiveness of the quantity supplied (or demanded) of a good or service to a change in its price. 


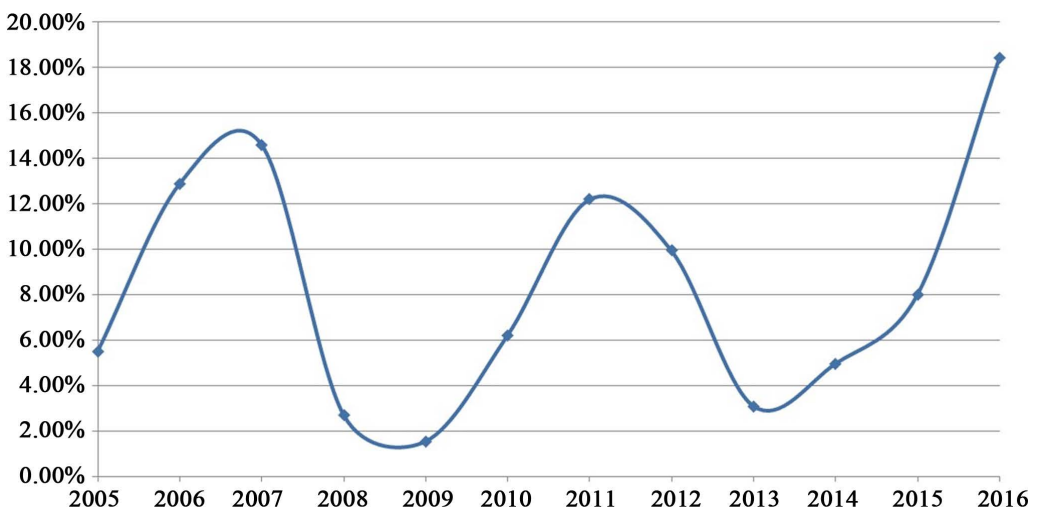

(a)

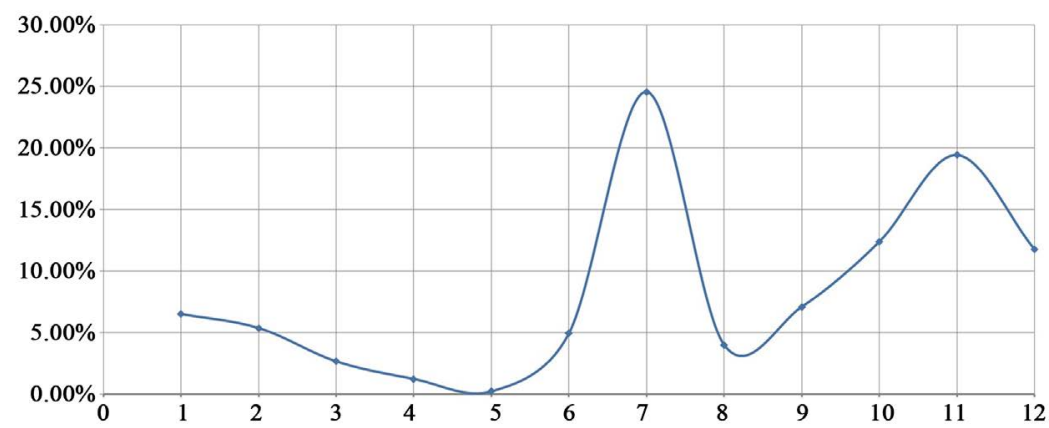

(b)

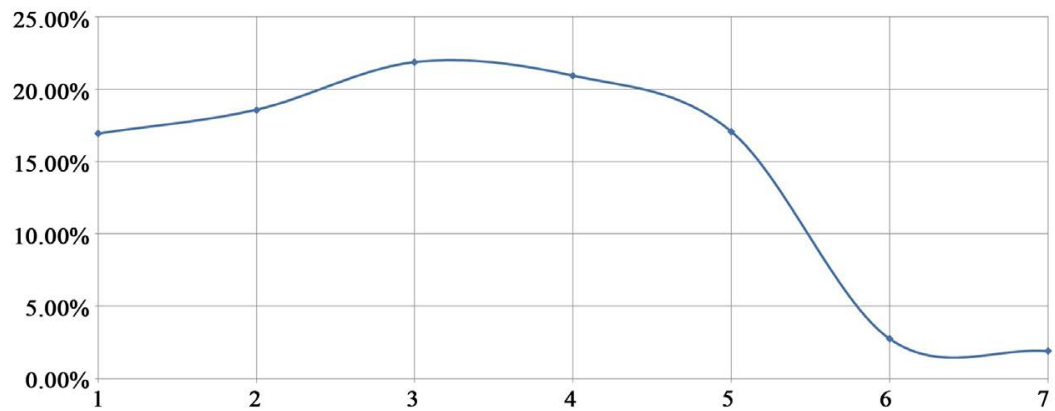

(c)

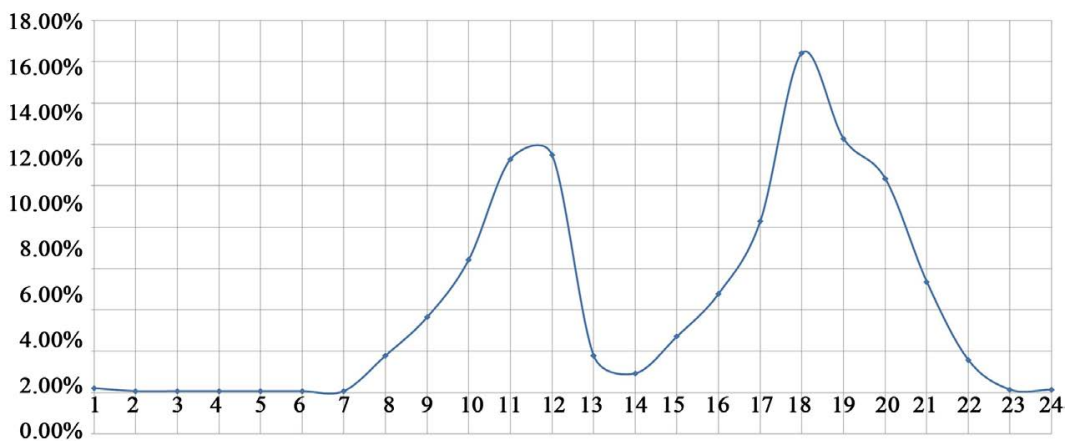

(d)

Figure 2. (a) Price spikes incidence per year. Source: Authors elaboration based on GME hourly data; (b) Price spikes incidence per Month ("1" = Jan, and so on). Source: Authors elaboration based on GME hourly data; (c) Price spikes incidence per Day of the week ("1" = Monday, and so on). Source: Authors elaboration based on GME hourly data; (d) Price spikes incidence per Hour. Source: Authors elaboration based on GME hourly data. 
The elasticity is defined as the percentage change in the quantity supplied divided by the percentage change in its price. Namely:

$$
e_{P}=\frac{\Delta Q / Q}{\Delta p / p}=\frac{\Delta Q}{\Delta p} \cdot \frac{p}{Q}
$$

where $e_{P}$ is the price elasticity, $Q$ is the good (or service) quantity, $\Delta Q$ its variation, $p$ the good (or service) price and $\Delta p$ its variation.

In terms of its absolute value, an elasticity coefficient lower than one is typically read as an inelastic response to price changes, while a value greater than one signals an elastic response to price changes. With reference to the value sign, supply elasticity is typically positive, while demand is typically negative.

Figure 3 reports a typical auction session, with its demand and offer curves, and the resulting closing price and quantity.

- Demand curve characteristics

It is important to analyze the actual bid and offer curves characteristics. The first evidence in Figure 3 is that the demand (bid) curve is highly inelastic, and that the main part of the demanded quantity is at "no price", so the buyers are willing to accept all resulting prices for the main part of the requested power. This means that the effect of prices variations is only slightly affecting the demanded quantity of electricity.

- Offer curve characteristics

The offer curve shows a completely different ongoing, which can be split into three main parts with different characteristics.

The first part (up to 23,000 MWh in Figure 3) is flat, and refers to offers at zero price, so it is due to producers willing to sell their production at whatever price the auction will determine (highly elastic). The second part (23,000 to 40,000 MWh in Figure 3) part is gradually rising, with a variable but limited slope (elastic). The third part (from around 40,000 MWh on in Figure 3) is almost vertical (inelastic).

One base reference coming from microeconomics is that, for a producer, it is worth selling the product as soon as its price is higher than its variable costs. In this way, all the variable costs needed for producing the output are covered, and

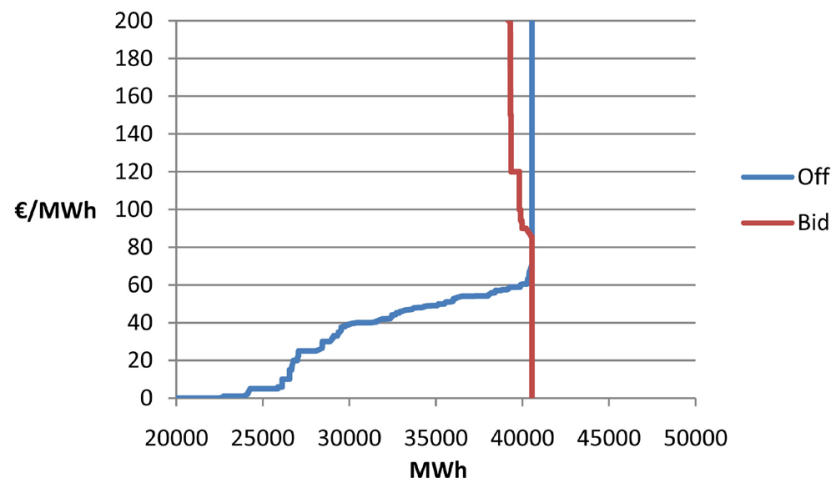

Figure 3. Actual Italian electric market bid/off curves. Source: Authors elaboration based on GME hourly data. 
if the price is higher than this threshold, the difference can also cover the fixed costs, and, after the coverage of fixed costs, produce some income.

The three parts of the offer curve reflect the technology differences among the producers. The first part is typically due to RES, characterized by almost no variable costs, so that any positive price gives a positive contribution to the producer revenue, thus, it is worth selling all the production at whatever price.

The second part is typically related to fuel based productions, characterized by a significant cost for each MWh of power production, which is different for different fuels and technologies. In this case, it is worth selling the production only when the fuel and, more in general, marginal costs are covered by the resulting price. As the different technologies (and different power plants) are characterized by different marginal costs (see Table 1), the resulting curve reflects these differences, and each time the price goes up, some more plant can be accepted for covering the electricity demand. This results in variable slopes for the curve.

The final part of the curve is due to possible but limited overproductions of some power plant, with high variable costs.

- Renewable sources impact

From the previous description, it is evident that the effect of any variability of RES offered quantity impacts on the first part of the offer curve. This happens quite often, as within the RES productions we typically have significant variations, e.g. due to the solar light daily variation, to the wind variations and to the river flows variations. These production variations impact on the zero price offers, continuously changing in a significant way its total volume.

Instead, the fuel-based productions have no significant variations within the day, so the second part of the curve is characterized by a relative stability.

As described above, the auction mechanism is based on the producers offers, ordered on the offered price.

Thus, a reduction in the offered quantity at zero price, actually shifts the supply curve, denoted by $S$ in Figure 4, to the left, e.g. as in the new curve $S$.

This horizontal shifting actually affects the auction results: as evident in Figure 4 , the clearing quantity falls from $q^{*}$ to $q^{\prime *}$ while the clearing price rises from $p^{*}$ to $p^{\prime *}$.

Table 1. Start-up times and marginal costs for some technologies.

\begin{tabular}{ccc}
\hline Power Plant technology & Guaranteed Cold Start-Up Time $[h]$ & Marginal Costs $[\epsilon / M W h]$ \\
\hline Wind turbine & $\infty$ & 1 \\
Hydroelectric power station & 0.02 & 1 \\
Gas turbine & 0.12 & 90 \\
Cogeneration plant (CHP) & 0.17 & 50 \\
Combined cycle gas turbine & 5 & 50 \\
Hard coal power plant & 6 & 60 \\
Lignite power plant & 9 & 40 \\
Nuclear power plant & 50 & 5
\end{tabular}

Data from [16] (start-up times) and [17] (2008) (marginal costs). 
Both demand and supply elasticity are fundamental, as a high elasticity determines small variations in the clearing price and quantity. Instead, rigidity increases the effect of variations to the clearing values. In particular when both curves are rigid, as when the demand volume is high, thus crossing the offer curve in its right side, near to the maximum production capability, even small variations can cause important jumps in the resulting price.

An example of this effect is highlighted in the following Figure 5, reporting the offer curve shift from 7 p.m. to 8 p.m. of the same day (11/09/2015), causing a price variation from 84.27 to $92.17 € / \mathrm{MWh}$ even if the demand, in the same hour, has had some reduction.

With reference to the Italian electricity market, Figure 6 reports the share of each of the main production technologies for year 2014, signaling an effective impact of RES.

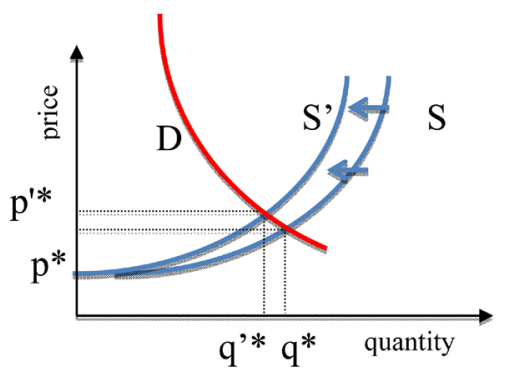

Figure 4. Effect of the RES production reduction on the auction clearing quantity and price. Source: Authors elaboration.

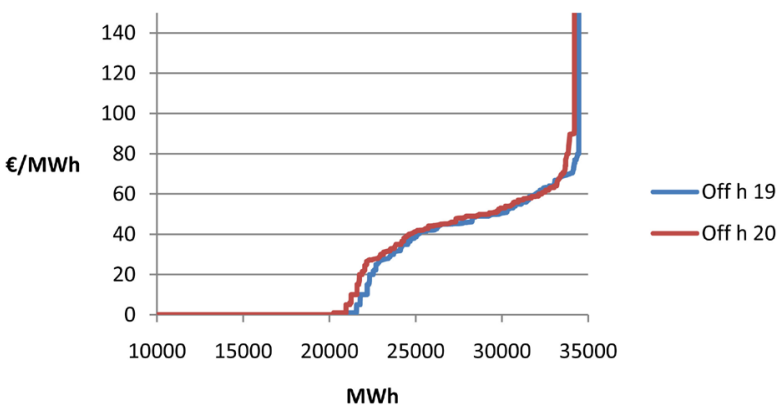

Figure 5. Example of supply shifting in the Italian day-ahead electricity market. Source: Authors elaboration based on GME hourly data.

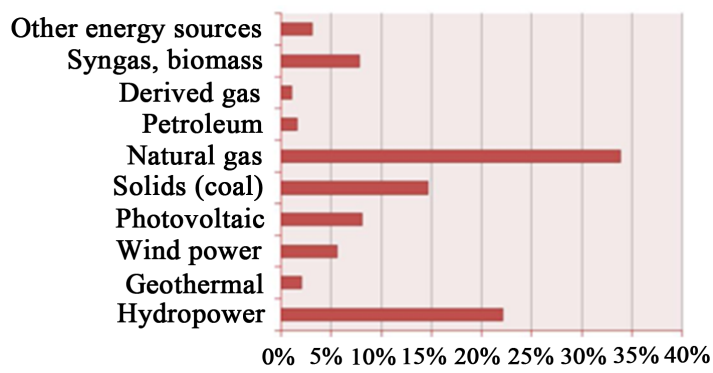

Figure 6. Electricity production sources for year 2014-Italy. Source: Terna annual report. 
For the reasons reported above, the changes in the zero offers (RES production), shifts to the left the offer curve, and, due to the rigidity of the demand curve, this results in significant variations in the auction closing price. But when the demanded production is near to the third (almost vertical) part of the offer curve, even small reductions in the zero offers can induce price spikes.

\section{Conclusions}

The electricity markets are extremely volatile and the electricity prices often exhibit abrupt spikes. This is one of the striking peculiarities of these markets. In order to face this price risk, futures and power derivatives have been settled by financial industry. The main goal of our paper is to explain the complex mechanisms that provoke price spikes, not adequately addressed in literature. Analyzing the Italian market, we showed that demand peaks only explain a small part of price spikes.

Thus, we have examined in detail the auction mechanism that characterizes the day-ahead electricity market.

Results show that the rigidity that characterizes both the demand curve and part of the supply curve is the fundamental determinant of price spikes.

More specifically, when demand values are high, both curves are characterized by a high rigidity, and even small variations of the demanded quantity or of the offered production have a high impact on the resulting clearing prices.

In this process, the variations of RES production turned out to be fundamental. In fact, even if at a first glance the RES production volume seems not impacting, as it is typically offered at zero price, in fact, it shifts the whole supply curve, and its effect results to be highly impacting.

\section{Acknowledgements}

This work was supported by Fondazione di Sardegna and Regione Autonomadella Sardegna.

\section{Conflicts of Interest}

The authors declare no conflicts of interest regarding the publication of this paper.

\section{References}

[1] Christensen, T.M., Hurn, A.S. and Lindsay, K.A. (2012) Forecasting Spikes in Electricity Prices. International Journal of Forecasting, 28, 400-411.

https://doi.org/10.1016/j.ijforecast.2011.02.019

[2] Clements, A.E., Herrera, R. and Hurna, A.S. (2015) Modelling Interregional Links in Electricity Price Spikes. Energy Economics, 51, 383-393. https://doi.org/10.1016/j.eneco.2015.07.014

[3] Handika, R., Truong, C., Trueck, S. and Weron, R. (2014) Modelling Price Spikes in Electricity Markets-The Impact of Load, Weather and Capacity. In: Prokopczuk, M., Ed., Energy Pricing Models. Recent Advances, Methods, and Tools, Palgrave 
Macmillan, Basingstoke, 195-221. https://doi.org/10.1007/978-1-137-37027-3_7

[4] Huisman, R. (2008) The Influence of Temperature on Spike Probability in Day-Ahead Power Prices. Energy Economics, 30, 2697-2704.

https://doi.org/10.1016/j.eneco.2008.05.007

[5] Janczura, J., Trück, S., Weron, R. and Wolff, R.C. (2013) Identifying Spikes and Seasonal Components in Electricity Spot Price Data: A Guide to Robust Modeling. Energy Economics, 38, 96-110. https://doi.org/10.1016/j.eneco.2013.03.013

[6] Manner, H., Türk, D. and Eichler, M. (2016) Modeling and Forecasting Multivariate Electricity Price Spikes. Energy Economics, 60, 255-265.

https://doi.org/10.1016/j.eneco.2016.10.006

[7] Mount, T.D., Ning, Y. and Cai, X. (2006) Predicting Price Spikes in Electricity Markets Using a Regime-Switching Model with Time-Varying Parameters. Energy Economics, 28, 62-80. https://doi.org/10.1016/j.eneco.2005.09.008

[8] Ullrich, C.J. (2012) Realized Volatility and Price Spikes in Electricity Markets: The Importance of Observation Frequency. Energy Economics, 34, 1809-1818. https://doi.org/10.1016/j.eneco.2012.07.003

[9] Weron, R. (2014) Electricity Price Forecasting: A Review of the State-of-the-Art with a Look into the Future. International Journal of Forecasting, 30, 1030-1081. https://doi.org/10.1016/j.ijforecast.2014.08.008

[10] Vespucci, M.T., Allevi, E., Gnudi, A. and Innorta, M. (2010) Cournot Equilibria in Oligopolistic Electricity Markets. IMA Journal of Management Mathematics, 21, 183-193. https://doi.org/10.1093/imaman/dpp004

[11] Bierbrauer, S.T. and Weron, R. (2004) Lecture Notes in Computer Science. Springer, Berlin, 859-867. https://doi.org/10.1007/978-3-540-25944-2_111

[12] Cartea, A. and Figueroa, M. (2005) Pricing in Electricity Markets: A Mean Reverting Jump Diffusion Model with Seasonality. Applied Mathematical Finance, 12, 313-335. https://doi.org/10.1080/13504860500117503

[13] Amjady, N. and Keynia, F. (2010) Electricity Market Price Spike Analysis by a Hybrid Data Model and Feature Selection Technique. Electric Power Systems Research, 80, 318-327. https://doi.org/10.1016/j.epsr.2009.09.015

[14] Lu, X., Dong, Z.Y. and Li, X. (2005) Electricity Market Price Spike Forecast with Data Mining Techniques. Electric Power Systems Research, 73, 19-29. https://doi.org/10.1016/S0378-7796(04)00125-7

[15] Voronin, S. and Partanen, J. (2013) Price Forecasting in the Day-Ahead Energy Market by an Iterative Method with Separate Normal Price and Price Spike Frameworks. Energies, 6, 5897-5920. https://doi.org/10.3390/en6115897

[16] Grimm, V. (2007) Einbindung von Speichernfürerneuerbare Energien in die Kraftwerkseinsatzplanung_Einfluss auf die Strompreise der Spitzenlast. PhD Thesis, Ruhr University Bochum, Bochum.

[17] Butler, L. and Neuhoff, K. (2008) Comparison of Feed-In Tariff, Quota and Auction Mechanisms to Support Wind Power Development. Renewable Energy, 33, 1854-1867. https://doi.org/10.1016/j.renene.2007.10.008 


\section{Appendix}

Table A1. Model 1: Probit, using 43,843 observations.

\begin{tabular}{cccccc}
\hline Variable & Coeff. & Std. error & $\mathrm{z}$ & P value & Significance \\
\hline const & -55.0557 & 8.88217 & -6.198 & $5.70 \mathrm{e}-10$ & $* * *$ \\
demand & 0.00407 & 0.00068 & 6.006 & $1.90 \mathrm{e}-09$ & $* * *$ \\
demand_lag2 & $-6.83276 \mathrm{e}-05$ & $7.03114 \mathrm{e}-06$ & -9.718 & $2.53 \mathrm{e}-22$ & $* * *$ \\
demand_lag5 & $2.48008 \mathrm{e}-05$ & $4.19369 \mathrm{e}-06$ & 5.914 & $3.34 \mathrm{e}-09$ & $* * *$ \\
demand^2 & $-1.03906 \mathrm{e}-07$ & $1.70983 \mathrm{e}-08$ & -6.077 & $1.22 \mathrm{e}-09$ & $* * *$ \\
demand^3 & $9.09128 \mathrm{e}-13$ & $1.42697 \mathrm{e}-13$ & 6.371 & $1.88 \mathrm{e}-10$ & $* * *$ \\
\hline
\end{tabular}

${ }^{* *}$ signals parameter significance at $1 \%,{ }^{* *}$ significance at $5 \%$ and ${ }^{*}$ significance at $10 \%$. McFadden R-squared 0.2409; Adjusted R-squared 0.2390.

Table A2. Model 2: Probit, using 43,843 observations.

\begin{tabular}{|c|c|c|c|c|c|}
\hline Variable & Coeff. & Std. error & $\mathrm{z}$ & $\mathrm{P}$ value & Significance \\
\hline Const & -76.83500 & 9.938140 & -7.731 & $1.06 \mathrm{e}-014$ & $* * *$ \\
\hline demand & 0.005528 & 0.000759 & 7.276 & $3.43 e-013$ & $* * *$ \\
\hline demand_lag2 & $-7.99335 \mathrm{e}-05$ & $7.86542 \mathrm{e}-06$ & -10.16 & $2.91 \mathrm{e}-024$ & $* * *$ \\
\hline demand_lag5 & $3.20417 \mathrm{e}-05$ & $4.69250 \mathrm{e}-06$ & 6.828 & $8.59 \mathrm{e}-012$ & $* * *$ \\
\hline demand $\wedge 2$ & $-1.43841 \mathrm{e}-07$ & $1.92410 \mathrm{e}-08$ & -7.476 & $7.68 \mathrm{e}-014$ & $* * *$ \\
\hline demand ${ }^{\wedge} 3$ & $1.27359 \mathrm{e}-012$ & $1.61226 \mathrm{e}-013$ & 7.899 & $2.80 \mathrm{e}-015$ & $* * *$ \\
\hline oil_price & -0.25669 & 0.036439 & -7.044 & $1.86 \mathrm{e}-012$ & $* * *$ \\
\hline oil_price_lag168 & 0.53456 & 0.057385 & 9.315 & $1.22 \mathrm{e}-020$ & $* * *$ \\
\hline oil_price_lag366 & -0.24342 & 0.024738 & -9.840 & $7.59 \mathrm{e}-023$ & $* * *$ \\
\hline gas_price & -4.08770 & 0.645664 & -6.331 & $2.44 \mathrm{e}-010$ & $* * *$ \\
\hline gas_price_lag168 & 5.92652 & 0.683609 & 8.669 & $4.34 \mathrm{e}-018$ & $* * *$ \\
\hline oil $^{\star}$ gas_price & 0.02302 & 0.007680 & 2.998 & 0.0027 & $* * *$ \\
\hline oil $^{*}$ gas_price_lag168 & -0.040030 & 0.007928 & -5.049 & $4.44 \mathrm{e}-07$ & $* * *$ \\
\hline
\end{tabular}

McFadden R-squared 0.3350; Adjusted R-squared 0.3307.

Historical time series for oil (Europe Brent Spot Price FOB-Dollars per Barrel) and gas (Henry Hub Natural Gas Spot Price-Dollars per Million Btu) come from on the US Energy Information Administration (http://www.eia.gov).

The oil and gas variables included in the regression are obtained on the base of daily values, and computed as the average price of the previous 30 days, on a rolling window. 